ARTICLE

DOI: $10.1038 / s 41467-018-06490-w$

\title{
Ultra-long-acting removable drug delivery system for HIV treatment and prevention
}

\author{
Martina Kovarova1, S. Rahima Benhabbour ${ }^{2}$, Ivana Massud ${ }^{3}$, Rae Ann Spagnuolo ${ }^{1}$, Brianna Skinner ${ }^{4}$, \\ Caroline E. Baker ${ }^{1}$, Craig Sykes ${ }^{5}$, Katie R. Mollan ${ }^{6}$, Angela D. M. Kashuba ${ }^{5}$, J. Gerardo García-Lerma ${ }^{3}$, \\ Russell J. Mumper ${ }^{2} \&$ J. Victor Garcia ${ }^{1}$
}

Non-adherence to medication is an important health care problem, especially in the treatment of chronic conditions. Injectable long-acting (LA) formulations of antiretrovirals (ARVs) represent a viable alternative to improve adherence to HIV/AIDS treatment and prevention. However, the LA-ARV formulations currently in clinical trials cannot be removed after administration even if adverse events occur. Here we show an ultra-LA removable system that delivers drug for up to 9 months and can be safely removed to stop drug delivery. We use two pre-clinical models for HIV transmission and treatment, non-human primates (NHP) and humanized BLT (bone marrow/liver/thymus) mice and show a single dose of subcutaneously administered ultra-LA dolutegravir effectively delivers the drug in both models and show suppression of viremia and protection from multiple high-dose vaginal HIV challenges in BLT mice. This approach represents a potentially effective strategy for the ultra-LA drug delivery with multiple possible therapeutic applications.

\footnotetext{
${ }^{1}$ Division of Infectious Diseases, Center for AIDS Research, Department of Medicine, School of Medicine, University of North Carolina at Chapel Hill, 120 Mason Farm Rd. CB 7042, Chapel Hill, NC 27599, USA. ${ }^{2}$ Division of Molecular Pharmaceutics, UNC Eshelman School of Pharmacy, University of North Carolina at Chapel Hill, 125 Mason Farm Rd. 4205, Chapel Hill, NC 27599, USA. ${ }^{3}$ Laboratory Branch, Division of HIV/AIDS Prevention, National Center for HIV/AIDS, Viral Hepatitis, STD, and TB Prevention, Centers for Disease Control and Prevention, 1600 Clifton Rd, MS G45, Atlanta, GA 30329, USA.

${ }^{4}$ Comparative Medicine Branch, Division of Scientific Resources, National Center for Emerging and Zoonotic Infectious Diseases, Centers for Disease Control and Prevention, Atlanta, GA 30329, USA. ${ }^{5}$ Division of Pharmacotherapy and Experimental Therapeutics, UNC Eshelman School of Pharmacy, University of North Carolina at Chapel Hill, 120 Mason Farm Rd. CB\#7361, Chapel Hill, NC 27599, USA. ${ }^{6}$ The University of North Carolina Center for AIDS Research, 3126 McGavran-Greenberg Hall, Chapel Hill, NC 27599, USA. Correspondence and requests for materials should be addressed to M.K. (email: kovarovm@med.unc.edu) or to J.V.G. (email: victor_garcia@med.unc.edu)
} 
A dherence to medication is essential to treatment success ${ }^{1}$. In most cases the extent to which patients are able to follow prescribed treatments determines the final outcome. This is particularly important in the treatment of chronic conditions like mental illnesses, hypertension, diabetes, and HIV/ AIDS $^{1}$. Sustained drug release has successfully improved adherence in patients with schizophrenia ${ }^{2}$ and as contraceptives ${ }^{3}$. Long-acting (LA) injectable formulations of ARV can increase adherence and effectiveness of HIV treatment and prevention ${ }^{4}$. In particular, LA formulations can (1) simplify dosing schedules, (2) reduce possible side effects, (3) provide constant concentration of drug, and (4) have a positive effect on patient's overall quality of life. LA-ARV formulations currently in clinical trials, are formulated as nanosuspensions for injections every 8 weeks $^{5-7}$ and it is impossible to remove the injected nanosuspension from the body in the case of a medical emergency.

To address this significant limitation and to extend the duration of treatment, an ultra-LA injectable and removable formulation for HIV PrEP based on in situ forming implant technology was developed. This allows drug administration by subcutaneous injection followed by implant solidification in vivo and subsequent biodegradation of the implant resulting in sustained drug release ${ }^{8,9}$. The efficacy of drug delivery via ultra-LA formulation in the context of HIV is evaluated in BLT humanized mice, systemically reconstituted with human hematopoietic cells ${ }^{10}$. BLT mice have been extensively used for HIV transmission, replication, and persistence studies ${ }^{11-14}$. Importantly, humanized BLT mice allow evaluation of HIV treatment and prevention strategies with a variety of transmitted/founder HIV-1 isolates via relevant routes of transmission.

\section{Results}

Preparation of ultra-LA dolutegravir. Dolutegravir, a highly effective second-generation HIV integrase strand transfer inhibitor with extensive track record of efficacy and safety ${ }^{15}$, was used for preparation of ultra-LA formulation. In addition to active drug, the formulation consists of two relatively low cost FDAapproved excipients: (1) poly(lactic-co-glycolic acid) (PLGA), a biodegradable copolymer that eventually and safely biodegrades and, (2) $\mathrm{N}$-methyl-2-pyrrolidone (NMP), a water miscible and biocompatible organic solvent ${ }^{16,17}$. Composition of the ultra-LA formulation was first optimized for release kinetics in vitro and then sustained delivery of dolutegravir in vivo (Fig. 1). The formulation contained dolutegravir/PLGA/NMP at a ratio 0.3:1:2 by weight, had a viscosity $845 \mathrm{cP}$ at $25^{\circ} \mathrm{C}$ (Brookfield Cone and Plate Digital Rheometer, $n=3$ ). Formulation stability was assessed as the ability to remain in solution (measured by dynamic light scattering, Zetasizer Nano ZS Particle Analyzer), and to maintain a stable dolutegravir concentration $(98 \%$ of the original a

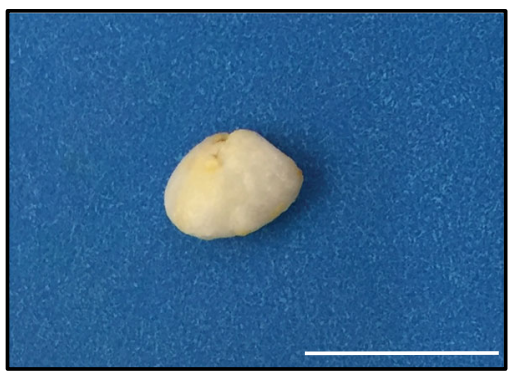

C

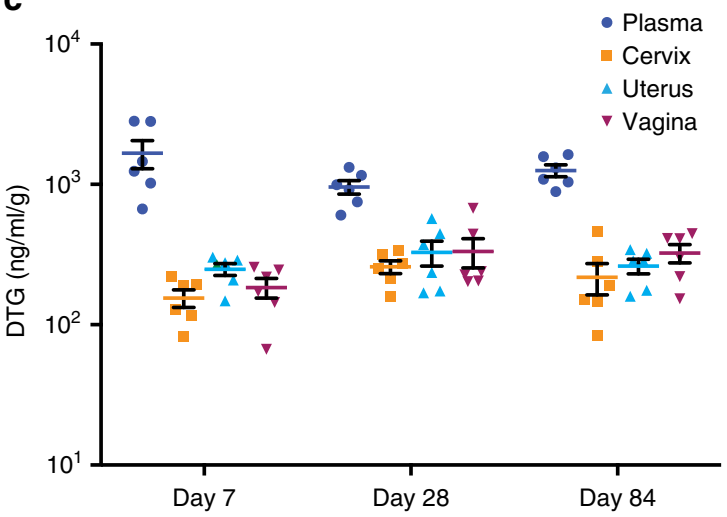

b

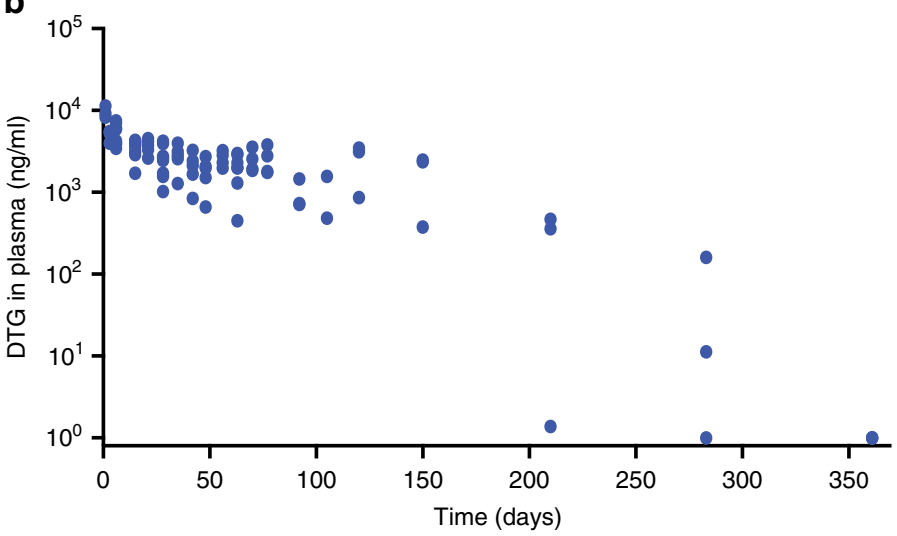

d

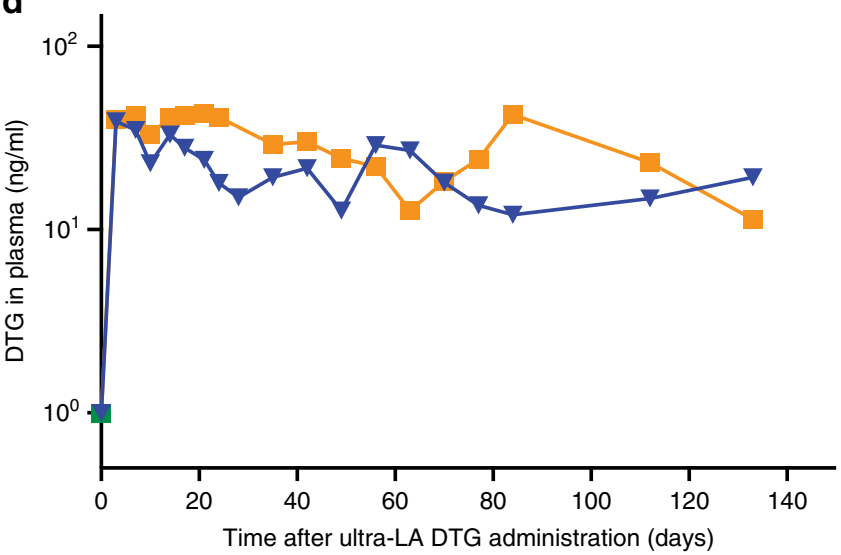

Fig. 1 Implant formation and dolutegravir concentration in plasma and female reproductive tract. a Solidified ultra-LA dolutegravir surgically removed 7 days after administration. Scale bar represents $1 \mathrm{~cm}$. b Pharmacological profile of NSG and BLT mice administered ultra-LA dolutegravir (250 mg/kg), five independent experiments, $n=21$. c Dolutegravir concentrations in plasma and parts of female reproductive tract 7, 28, and 84 days after subcutaneous administration of ultra-LA dolutegravir $(250 \mathrm{mg} / \mathrm{kg}$ ). The data from two independent experiments are shown, $n=6$ for each time point. Shown are individual animals and the means \pm s.e.m. (standard error of the mean). Tissue density of $1 \mathrm{~g} / \mathrm{ml}$ was used to compare dolutegravir concentration between tissues and plasma. d Plasma concentration of dolutegravir in 2 rhesus macaques administered $1 \mathrm{ml}$ of formulation used in (b) and $\mathbf{c}(100 \mathrm{mg}$ of dolutegravir) 


\begin{tabular}{|c|c|c|c|}
\hline & Day 7 & Day 28 & Day 84 \\
\hline Cervix & 0.136 & 0.277 & 0.184 \\
\hline Uterus & 0.191 & 0.345 & 0.208 \\
\hline Vagina & 0.160 & 0.354 & 0.252 \\
\hline Mean \pm SD & $0.162 \pm 0.03$ & $0.326 \pm 0.04$ & $0.215 \pm 0.03$ \\
\hline
\end{tabular}

Female NSG mice $(n=18)$ received $250 \mathrm{mg} /$ ultra-LA dolutegravir subcutaneously and dolutegravir concentration in plasma and isolated organs of the female reproductive tract was analyzed at day $7(n=6), 28(n=6)$, and $84(n=6)$ using a LC-MS/MS method. Mean of ratios tissue/plasma is shown

concentration) measured by HPLC analysis. Dolutegravir was chemically stable in this formulation at $25^{\circ} \mathrm{C}$ for at least 6 months. In the aqueous environment in vitro (0.01 M PBS, $\mathrm{pH}$ $=7.4,2 \%$ solutol) solidification of the implant was instantaneous.

Pharmacokinetics of ultra-LA dolutegravir. For an initial in vivo evaluation, anesthetized female NSG and BLT mice received a single subcutaneous injection of the ultra-LA dolutegravir on their back $(5.5-7.0 \mathrm{mg}$ dolutegravir in $50-80 \mu \mathrm{l})$. The injected formulation first formed a hard translucent globule under the skin that turned yellowish white (within $48 \mathrm{~h}$ of administration) as the formulation solidified. The formulation was well tolerated by the mice and no injection site reactions or other signs of overt toxicity, changes in behavior, movement, water consumption or weight loss were noted. For the purpose of observing the nature of the implant and to confirm that it could be readily removed from the mice, 1 week after administration a small incision was made near the location of the implant in one of the mice allowing rapid removal of the implant from the mouse (Fig. 1a). The rest of the mice were used for in vivo pharmacokinetic analysis of drug release (Fig. 1b). Plasma concentrations of dolutegravir were quantitated using a validated high-performance liquid chromatography-tandem mass spectrometry LC/MS-MS method $^{18}$. Non-compartmental analysis of the median composite pharmacokinetic (PK) profile demonstrated a biexponential decay. After an initial 1st order decline in plasma concentrations, the release of dolutegravir approached zero-order kinetics. Plasma concentration of dolutegravir was ten times greater than the protein adjusted (PA)- $\mathrm{IC}_{90}$ for at least 5 months post administration. Even at 283 days after ultra-LA dolutegravir administration $1 / 3$ mice still had detectable dolutegravir in plasma. We then used a sparse PK analysis to compare the concentration of plasma dolutegravir between BLT humanized and nonhumanized mice. Our results demonstrated similar pharmacokinetics of dolutegravir in both types of mice (Supplementary Fig. 1).

Concentration of dolutegravir was also evaluated in the female reproductive tract (FRT) in 14 NSG mice receiving a single subcutaneous injection of ultra-LA dolutegravir. Vagina, cervix, uterus, and plasma from treated mice were collected 1, 4, and 12 weeks post administration and dolutegravir concentrations determined (Fig. 1c). One week after ultra-LA dolutegravir administration, the median concentration of dolutegravir in plasma, vagina, cervix, and uterus were $1350 \mathrm{ng} / \mathrm{ml}, 196 \mathrm{ng} / \mathrm{mg}$, $158 \mathrm{ng} / \mathrm{mg}$, and $272 \mathrm{ng} / \mathrm{ml}$, respectively. One month post administration, the median dolutegravir concentrations were $958 \mathrm{ng} / \mathrm{ml}, 233 \mathrm{ng} / \mathrm{mg}, 262 \mathrm{ng} / \mathrm{mg}$, and 303, ng/mg, respectively, and 12 weeks post administration the median concentrations were $1200 \mathrm{ng} / \mathrm{ml}, 356 \mathrm{ng} / \mathrm{mg}, 170 \mathrm{ng} / \mathrm{mg}$, and $284 \mathrm{ng} / \mathrm{mg}$, respectively (Fig. 1c, Table 1). Differences in DTG concentrations within each compartment (vagina, cervix, uterus, and plasma) comparing 1 week, 4 weeks, and 12 weeks ( $n=6$ per group) did not reach statistical significance (Kruskal-Wallis test plasma $p=$ 0.21 , cervix $p=0.09$, uterus $p=0.70$, vagina $p=0.17$ ). Observations were combined over weeks 1,4 , and 12 to evaluate whether plasma concentrations were higher than tissue concentrations for each tissue type separately. Dolutegravir concentrations in plasma were higher than in tissue for each of the three tissue types for every animal (Wilcoxon signed-rank $p<0.001$ for cervix, uterus, and vagina analyses, respectively). Together, these results demonstrate the sustained in vivo release of dolutegravir into plasma and its efficient penetration into tissues of the female reproductive tract.

To assess safety and drug release profile of the ultra-long-acting formulation of dolutegravir in a large animal model, two rhesus macaques were subcutaneously administered the ultra-LA dolutegravir formulation $(100 \mathrm{mg})$. Animals were monitored for signs of toxicity and skin reactions at the injection site, including erythema, edema, and hematoma formation, presence of induration, and any other lesions such as abscesses, necrosis, dehiscence, or local inflammation twice a week. The implants were well tolerated with little or no sign of toxicity for 5 months (last point analyzed). Administration of the ultra-long-acting formulation of dolutegravir resulted in sustained dolutegravir concentration in plasma for more than 140 days (Fig. 1d). These results demonstrate the feasibility of ultra-long-acting dolutegravir delivery system for sustained delivery in rhesus macaques. However, this formulation originally developed for BLT mice will have to be further optimized prior to efficacy studies in macaques and its potential future applications in humans.

Inhibition of HIV-1 replication ex vivo. Having demonstrated sustained concentration of dolutegravir in plasma of both mice and macaques and in tissues from mice we proceeded to evaluate its antiviral activity. Serum obtained from the ultra-LA dolutegravir-treated mice in Fig. 1c demonstrated strong, concentration dependent antiviral activity (Fig. 2a). Specifically, a one hundredth-fold dilution of serum was able to block in vitro viral infection by $>86 \%$ when collected 7 or 28 days post administration (median $89 \%$, range $86.4 \%-90.8 \%$ and median $86 \%$, range $74.1 \%-87.9 \%$ for 7 and 28 days, respectively). A 100 -fold dilution of serum was also able to block HIV infection by $66 \%$ when collected 84 days post ultra-LA dolutegravir administration (range 63.5\%-67.0\%) (Fig. 2b). Statistical analysis of the antiviral activity present in serum demonstrated a strong correlation with dolutegravir concentrations (Kendall rank correlation coefficient 0.75; 95\% CI: 0.65-0.85) (Fig. 2c).

Inhibition of HIV-1 replication in vivo. To establish the in vivo inhibitory effect of dolutegravir administered via the ultra-LA dolutegravir formulation on HIV replication, eight BLT humanized mice were first infected intravenously with HIV-1 $1_{\text {JR-CSF }}$ $\left(3 \times 10^{4}\right.$ TCIU) (Fig. 3a, Table 2$)$. HIV-RNA was readily detected in plasma from all exposed mice 2 weeks after exposure (median $1.97 \times 10^{6}$ copies $/ \mathrm{ml}$, range $0.65-8.50 \times 10^{6}$ copies $\left./ \mathrm{ml}\right)$. Two weeks post infection, mice received a single dose of ultra-LA dolutegravir- or placebo administered via subcutaneous injection ( $n=4$ for each group). Dolutegravir plasma concentrations in treated mice were sustained throughout the entire experiment (Fig. 3b). Placebo-treated mice maintained high concentration of plasma HIV-RNA. In contrast, strong suppression of HIV replication $(\sim 1-2 \log )$ was noted in all mice treated with the ultraLA dolutegravir formulation (Fig. 3c, d). In one mouse, viral load fell below the level of quantitation (LOQ, 1375 copies of HIV$\mathrm{RNA} / \mathrm{ml}$ ) as early as 2 weeks post administration (Fig. 3c). Plasma viral load AUC was smaller in the ultra-long-acting dolutegravir group compared to the placebo group, $p=0.03$ (exact 

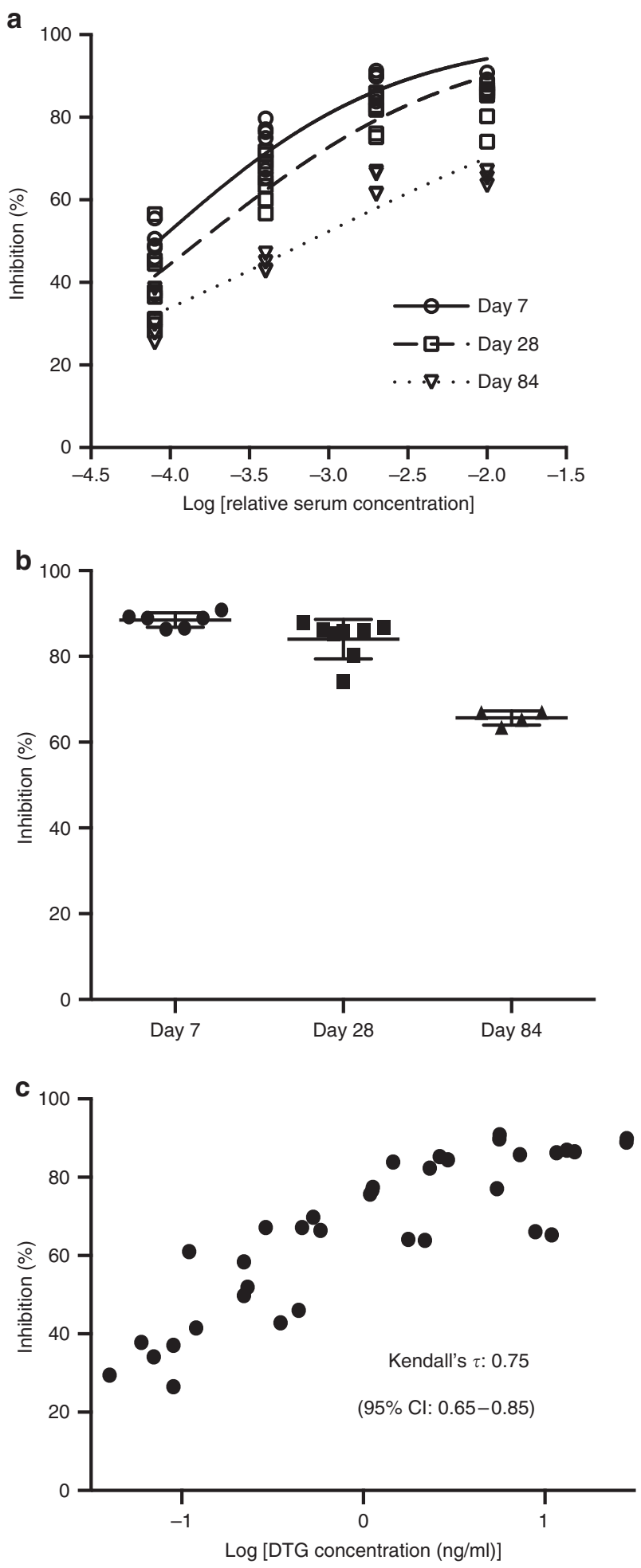

Fig. 2 In vitro inhibition of HIV-1 infection with serum from ultra-LA dolutegravir-treated mice. Serum from female NSG mice administered with ultra-LA dolutegravir $(250 \mathrm{mg} / \mathrm{kg})$ collected at days $7(n=3), 28(n=4)$, and $84(n=2)$ was used for a TZM-bl cell-based assay (measured in duplicates). a Inhibition of HIV-1 infection (\%) with various dilution of serum. Solid lines indicate nonlinear curve fit for the data. $\mathbf{b}$ Comparison of in vitro inhibitory activity of $1 \%$ serum collected from ultra-LA dolutegravir-treated NSG mice at the indicated time points (means \pm s.e.m). c Comparison of in vitro inhibitory activity (\%) of serum from ultra-LA dolutegravir-treated mice and $\log _{10}$ concentration of dolutegravir. A non-parametric rank-based correlation analysis accounting for clustered observations (Kendall's tau) was used
Wilcoxon-Mann-Whitney test, $n=8$ ). Virus RNA from plasma of mice treated with ultra-LA dolutegravir for 19 and 50 days were sequenced to determine whether mutations associated with drug resistance were acquired during this course of dolutegravir monotherapy. At day 19 bulk RNA sequences were obtained from the three mice with detectable viral loads. All three had a single nucleotide substitution resulting in an amino acid change at position $157(\mathrm{E} \rightarrow \mathrm{K})$. At day 50, viral RNA from all four-treated mice was analyzed. At this time point, all three mice analyzed at day 19 had mutated from $157 \mathrm{~K}$ to $157 \mathrm{Q}$. In addition, in one mouse a mutation was also detected at position $263(\mathrm{R} \rightarrow \mathrm{K})$. On day 50, the viral RNA from the mouse that was below detection at day 19 and thus could not be analyzed, had a mutation at position $157(\mathrm{E} \rightarrow \mathrm{K})$. Sequencing of individual clones from all viral RNAs obtained at days 19 and 50 revealed the presence of several other mutations (Table 3). The majority of them were naturally occurring polymorphic substitutions. Interestingly, both the $\mathrm{R} 263 \mathrm{~K}$ and $\mathrm{E} 157 \mathrm{Q}$ mutations were found in $2 / 8$ clones from one mouse. Together, these two mutations have been shown to increase the resistance of HIV to dolutegravir in vitro ${ }^{19}$.

To determine the effect of ultra-LA dolutegravir on the concentration of HIV-RNA in the female reproductive tract mice were lavaged at the indicated time points and samples analyzed for the presence of HIV-RNA and dolutegravir concentrations. Within 2-3 weeks of treatment the concentration of HIV RNA in cervico-vaginal secretions (CVS) rapidly decreased below LOQ (81 HIV-RNA copies per $60 \mu \mathrm{l}$ ) with transient low-level viral increases in two mice (Fig. 3e, f). These results indicate that despite the observed lower concentration of dolutegravir in the FRT compared to plasma (Table 1), the dolutegravir concentration in FRT was sufficient to efficiently suppress viral replication (Table 2). A slow decrease in CVS HIV-RNA was also observed in the placebo-treated mice, most likely as a result of the dramatic reduction in $\mathrm{CD} 4 \mathrm{~T}$-cell numbers occurring during HIV infection in the FRT (Fig. $3 \mathrm{~h})^{11}$. In contrast to the dramatic depletion of $\mathrm{CD} 4{ }^{+} \mathrm{T}$ cells noted in CVS from control (i.e., not treated) mice, in ultra-LA dolutegravir-treated mice, $\mathrm{CD} 4 \mathrm{~T}$-cell numbers progressively increased to the pre-exposure levels. $\mathrm{CD} 4^{+} \mathrm{T}$-cell percentage AUC was larger for all mice in the ultra-long-acting dolutegravir group compared to the control group, $p=0.03$ (exact Wilcoxon-Mann-Whitney test, $n=8$ ) further demonstrating the efficacy of ultra-LA dolutegravir treatment on systemic HIV infection (Fig. 3g, h).

Protection from vaginal HIV acquisition. To evaluate the potential of the ultra-LA dolutegravir to prevent vaginal HIV transmission, BLT mice ( $n=5$ per group) were subcutaneously administered ultra-LA dolutegravir (treated mice) or placebo (control mice) (Fig. 4a). Seven days later, mice were challenged vaginally with a high dose of one of two transmitted/founder viruses HIV- $1_{\text {CHO40 }}\left(3.0 \times 10^{5}\right.$ TCIU, 2 controls, three treated mice) or HIV-1 $1_{\text {THRO }}\left(3.5 \times 10^{5}\right.$, three controls, two treated mice). The two control mice exposed to HIV- $1_{\mathrm{CH} 040}$ became plasma HIV-RNA positive within 2 weeks after challenge and $2 / 3$ control mice challenged with HIV-1 $1_{\mathrm{THRO}}$ became plasma HIV-RNA positive within 3 weeks after the challenge (Fig. 4b). All ultra-LA dolutegravir-treated mice remained HIV negative after the first exposure. Six weeks after first challenge, ultra-LA dolutegravirtreated mice were challenged vaginally a second time with a high dose of HIV-1 $1_{\mathrm{CH} 040}\left(3.0 \times 10^{5} \mathrm{TCIU}\right)$. One-treated mouse became HIV-RNA positive 1 week after the second challenge, and sequence analysis identified the breakthrough virus as HIV$1_{\mathrm{CH} 040}$ with no mutations in the HIV integrase gene. All other treated mice (4/5) remained negative for plasma HIV-RNA (Fig. $4 \mathrm{~d}$, Table 4). Two different but complementary approaches were 
a

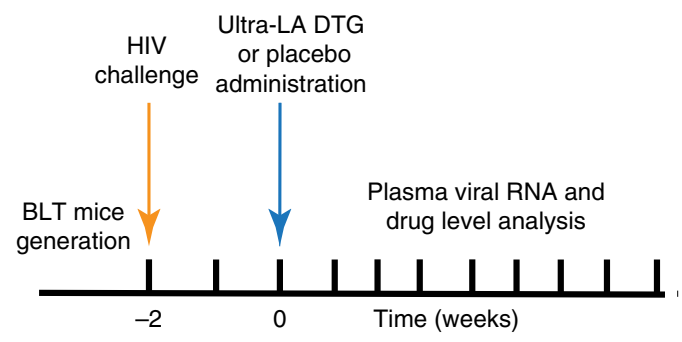

C

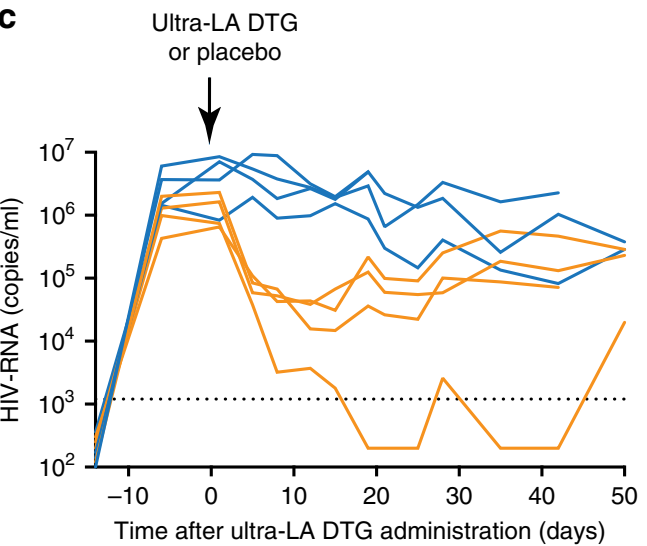

Ultra-LA DTG
or placebo

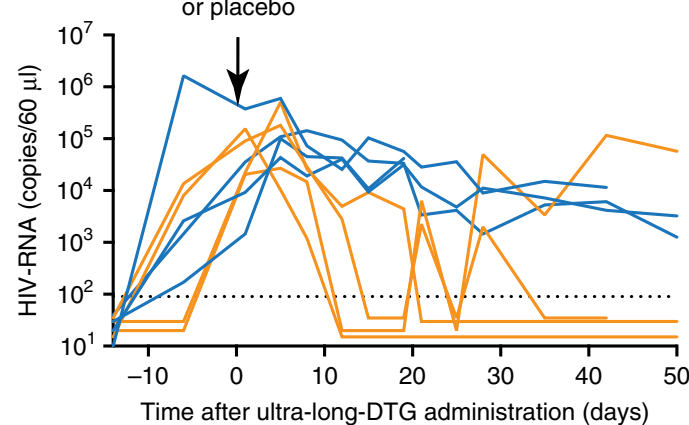

g

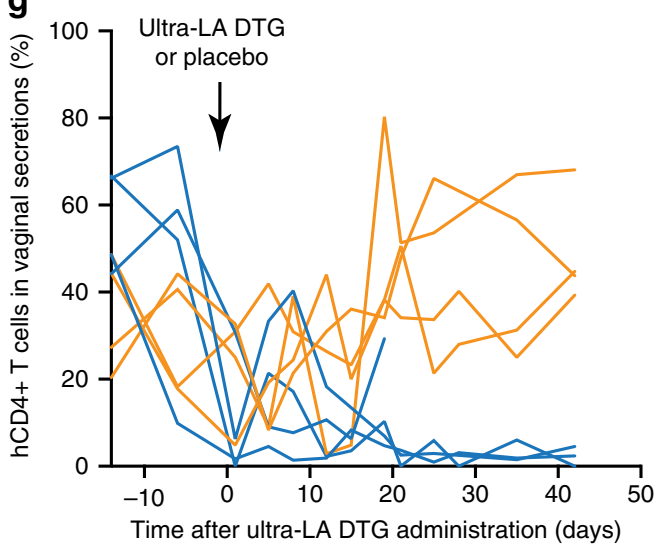

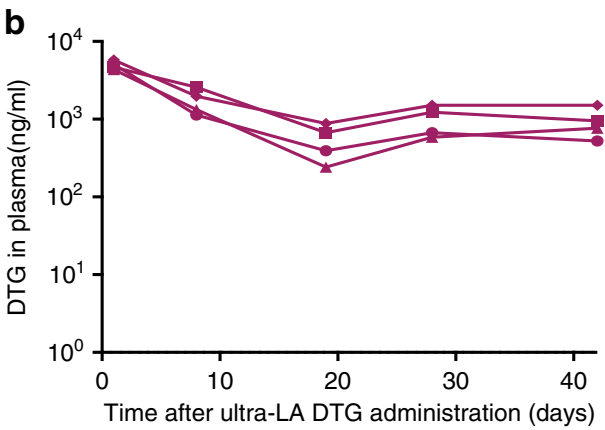

d
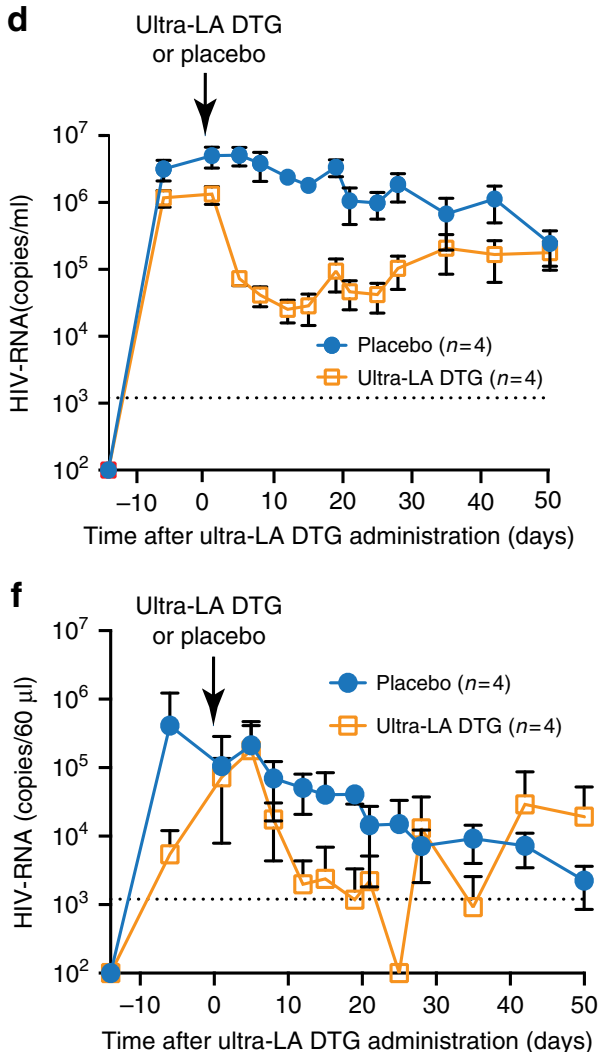

h

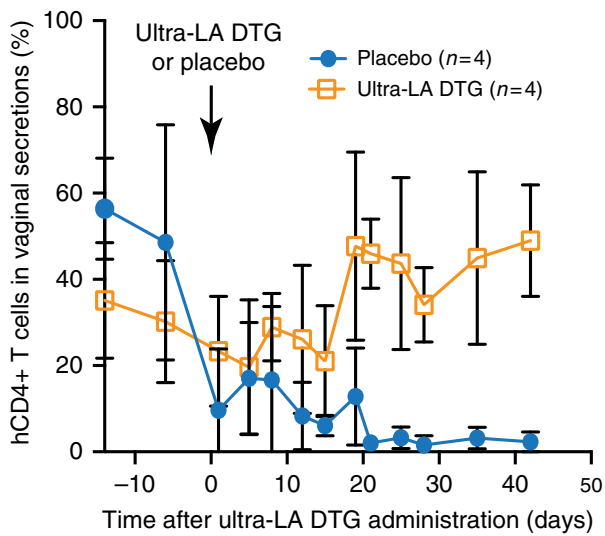

Fig. 3 Suppression of systemic HIV infection by ultra-LA dolutegravir. a Experimental design. BLT mice infected with HIV-1 JRC-SF were subcutaneously administered ultra-LA dolutegravir $(n=4)$ or placebo $(n=4)$ and monitored for plasma dolutegravir and HIV-RNA concentrations. $\mathbf{b}$ Concentration of dolutegravir in plasma from ultra-LA dolutegravir-treated mice. Plasma HIV-RNA concentration in individual mice $\mathbf{c}$ or means \pm s.e.m. d HIV-RNA in cervico-vaginal secretions (CVS) of individual mice (e) or means \pm s.e.m. $\mathbf{f}$ CD4 ${ }^{+}$T cells (relative amount of CD3 ${ }^{+}$cells) in CVS of individual mice ( $\mathbf{g}$ ) or means \pm s.e.m. $\mathbf{h}$ Yellow lines in $\mathbf{c}, \mathbf{e}$, and $\mathbf{g}$ ultra-long-acting dolutegravir-treated mice, blue lines placebo-treated mice. Experiment was conducted once 


\begin{tabular}{|lllll|}
\hline Table 2 HIV-1-RNA suppression by ultra-LA dolutegravir \\
Mouse & $\begin{array}{l}\text { hCD45 } \\
\text { (\%) }\end{array}$ & $\begin{array}{l}\text { hCD4 } \\
\text { (\%) }\end{array}$ & $\begin{array}{l}\text { Nadir (HIV- } \\
\text { RNA copies/ } \\
\text { ml plasma) }\end{array}$ & $\begin{array}{l}\text { Duration of } \\
\text { suppression below } \\
\text { LOQ in CVS (days) }\end{array}$ \\
\hline S1 & 37.9 & 76.1 & LOQ & 54 \\
S2 & 60.3 & 77.5 & $14,746.3$ & 27 \\
S3 & 43.6 & 71.5 & $38,282.0$ & 16 \\
S4 & 53 & 75.6 & $30,863.0$ & 41 \\
Mean & 48.7 & 75.2 & 21,022 & 33.5 \\
SD & 9.9 & 2.56 & 17,000 & 15.0 \\
\hline
\end{tabular}

BLT mice with indicated amount of human $\mathrm{CD}_{4} 5^{+}$(hCD45) cells and human $\mathrm{CD} 3^{+} \mathrm{CD} 4^{+}$ ( $\left(\mathrm{CD} 4\right.$ ) in peripheral blood were intravenously infected with HIV-1 JRC-SF $_{\text {and }}$ anded with ultraLA dolutegravir formulation $(250 \mathrm{mg} / \mathrm{kg}$ ) 3 weeks later. Limit of quantitation (LOQ) was 1375 copies/ml in plasma and 81 copies $/ 60 \mu$ in CVS

CVS cervico-vaginal lavage, SD standard deviation

\begin{tabular}{|c|c|c|c|}
\hline Mouse & $\begin{array}{l}\text { Dolutegravir } \\
\text { exposure (days) }\end{array}$ & $\begin{array}{l}\text { Identified } \\
\text { mutations }\end{array}$ & $\begin{array}{l}\text { Clones with the } \\
\text { mutation/ Clones } \\
\text { analyzed }\end{array}$ \\
\hline \multirow[t]{2}{*}{$\mathrm{S1}$} & 19 & NA & NA \\
\hline & 50 & E157K & $5 / 5$ \\
\hline \multirow[t]{8}{*}{ S2 } & 19 & E157K & $1 / 9$ \\
\hline & & $\begin{array}{l}\text { E157K+Q35K } \\
+Q 85 K+R 269 G\end{array}$ & $1 / 9$ \\
\hline & & V260A & $1 / 9$ \\
\hline & 50 & R269K & $1 / 9$ \\
\hline & & W243stop & $1 / 9$ \\
\hline & & E157K & $2 / 6$ \\
\hline & & E157Q & $1 / 6$ \\
\hline & & R263K & $1 / 6$ \\
\hline \multirow[t]{5}{*}{ S3 } & 19 & E157K & $2 / 5$ \\
\hline & & K159N & $1 / 5$ \\
\hline & & $\mathrm{D} 3 \mathrm{R}+\mathrm{G} 4 \mathrm{E}$ & $1 / 5$ \\
\hline & 50 & E157Q & $1 / 5$ \\
\hline & & $\begin{array}{l}\text { E157Q+R166K } \\
+\mathrm{D} 41 \mathrm{~N}+\mathrm{V} 281 \mathrm{M}\end{array}$ & $1 / 5$ \\
\hline \multirow[t]{6}{*}{ S4 } & 19 & D229G & $1 / 9$ \\
\hline & 50 & G70K & $1 / 8$ \\
\hline & & D6E & $1 / 8$ \\
\hline & & E157Q & $1 / 8$ \\
\hline & & R263K & $1 / 8$ \\
\hline & & R263K+E157Q & $2 / 8$ \\
\hline
\end{tabular}

BLT humanized mice infected intravenously with HIV-1 $1_{\mathrm{JR}-\mathrm{CSF}}\left(3 \times 10^{4} \mathrm{TCIU}\right)$ received a single dose of ultra-LA dolutegravir $(n=4)$ subcutaneously. Viruses in plasma at day 19 and 50 of the ultra-LA dolutegravir treatment were cloned and sequenced. Mutation previously described or identified as providing resistance to dolutegravir in bold

used to exclude the possibility that HIV-1 was transmitted but suppressed due to the continuous presence of dolutegravir. First, two mice without evidence of HIV-RNA in plasma were collected 11 and 13 weeks post ultra-LA dolutegravir administration for tissue HIV-DNA analysis. No evidence of HIV DNA was noted in any of the tissues analyzed confirming systemic protection from infection. Second, the ultra-LA dolutegravir implant was surgically removed in the remaining two HIV-1-negative mice 15 weeks post-implantation. Implant removal resulted in a rapid decrease of plasma dolutegravir concentrations $(>1 \log$ within first 3 days after the removal) (Fig. 4f). After implant removal, no HIV-RNA was detected in plasma (Fig. 4c). Four weeks postremoval of the ultra-LA dolutegravir mice were killed, tissues were collected and analyzed for the presence of cell-associated HIV-DNA. No evidence of HIV-DNA was found in any of the tissues analyzed confirming that the lack of viremia after ultra-LA dolutegravir removal was not due to an occult infection masked by the continuous presence of high concentration of drug (Table 4). Rather these results strongly indicate that these four mice were fully protected from two high dose vaginal exposures to HIV 6 weeks apart.

In order to establish a possible cause for the single breakthrough infection noted above, plasma drug concentrations throughout the course of the experiment were analyzed. The concentration of dolutegravir in plasma of $4 / 5$ treated mice was maintained at $2805 \mathrm{ng} / \mathrm{ml}$ (median, range $1510-4510 \mathrm{ng} / \mathrm{ml}$ ) for 11 weeks. In the mouse with the breakthrough infection, plasma dolutegravir concentration began to slowly decrease 3 weeks after injection. At the time of the second viral challenge, the plasma dolutegravir concentration was $659 \mathrm{ng} / \mathrm{ml}$. Plasma dolutegravir concentration continued to drop and by 11 weeks post ultra-LA dolutegravir administration it was below $10 \mathrm{ng} / \mathrm{ml}$ (Fig. 4e). These results suggest that the breakthrough infection is likely due to the lower concentrations of dolutegravir in this mouse.

\section{Discussion}

The HIV epidemic continues to be a significant health concern worldwide. In 2016, 36.7 million people were living with $\mathrm{HIV}^{20}$. Among promising preventive interventions is pre-exposure prophylaxis (PrEP), in which ARVs are taken by HIV-negative people before potential exposure to the virus. Clinical studies established that daily oral PrEP with Truvada ${ }^{\circledR}$ can prevent HIV infection among high-risk populations ${ }^{21-25}$. However, recent clinical trials demonstrate that lack of adherence to the indicated drug regimen is common, resulting in lack of protection from HIV infection ${ }^{26,27}$.

In the specific case of HIV prevention, the lack of adherence by clinical trial participants has served to highlight the urgent need for drug delivery systems capable of offering long-term protection from HIV infection ${ }^{26,27}$. Two LA-ARV formulations for HIV PrEP are in clinical trials. Cabotegravir, an integrase strand transfer inhibitor (INSTI), is in phase IIa and IIb/III clinical trials $^{28}$ and rilpivirine, a non-nucleoside reverse transcriptase inhibitor (NNRTI), is in a phase II clinical trial ${ }^{29}$. Both drugs are formulated as nanosuspensions for LA intramuscular injections every 8 weeks $^{5-7}$. Major limitations of this type of drug formulations are the complete inability to remove the injected nanosuspension from the body in the case of a medical emergency and the inability of co-formulation of two or more drugs. Removal of LA formulations is essential to circumvent adverse reactions or to prevent long-term sub-therapeutic drug exposure after PrEP discontinuation. These concerns are currently being partially addressed by an oral regimen of drug for 5 weeks prior to the administration of the LA formulation and by daily oral administration of Truvada for up to 1 year at the end of a dosing regimen ${ }^{7}$. Given the documented evidence of lack of compliance with this approach, these options are likely not appropriate for the targeted populations.

Humanized mouse models were used for pre-clinical efficacy assessment of LA formulations of ARVs. A nanosuspension of crystalline rilpivirine, administered intramuscularly, protected BLT mice from a single vaginal high-dose HIV-1 challenge 1 week after drug administration and provide partial protection 4 weeks after drug administration ${ }^{12}$. Similarly, single subcutaneous dose of LA raltegravir significantly protected BLT mice from vaginal HIV acquisition 4 weeks after drug administration $^{13}$. Recently, a lipophilic modified DTG prodrug encapsulated into poloxamer nanoformulations significantly protected CD34+ humanized mice from the HIV-1 for 2 weeks ${ }^{30}$. These results 
a
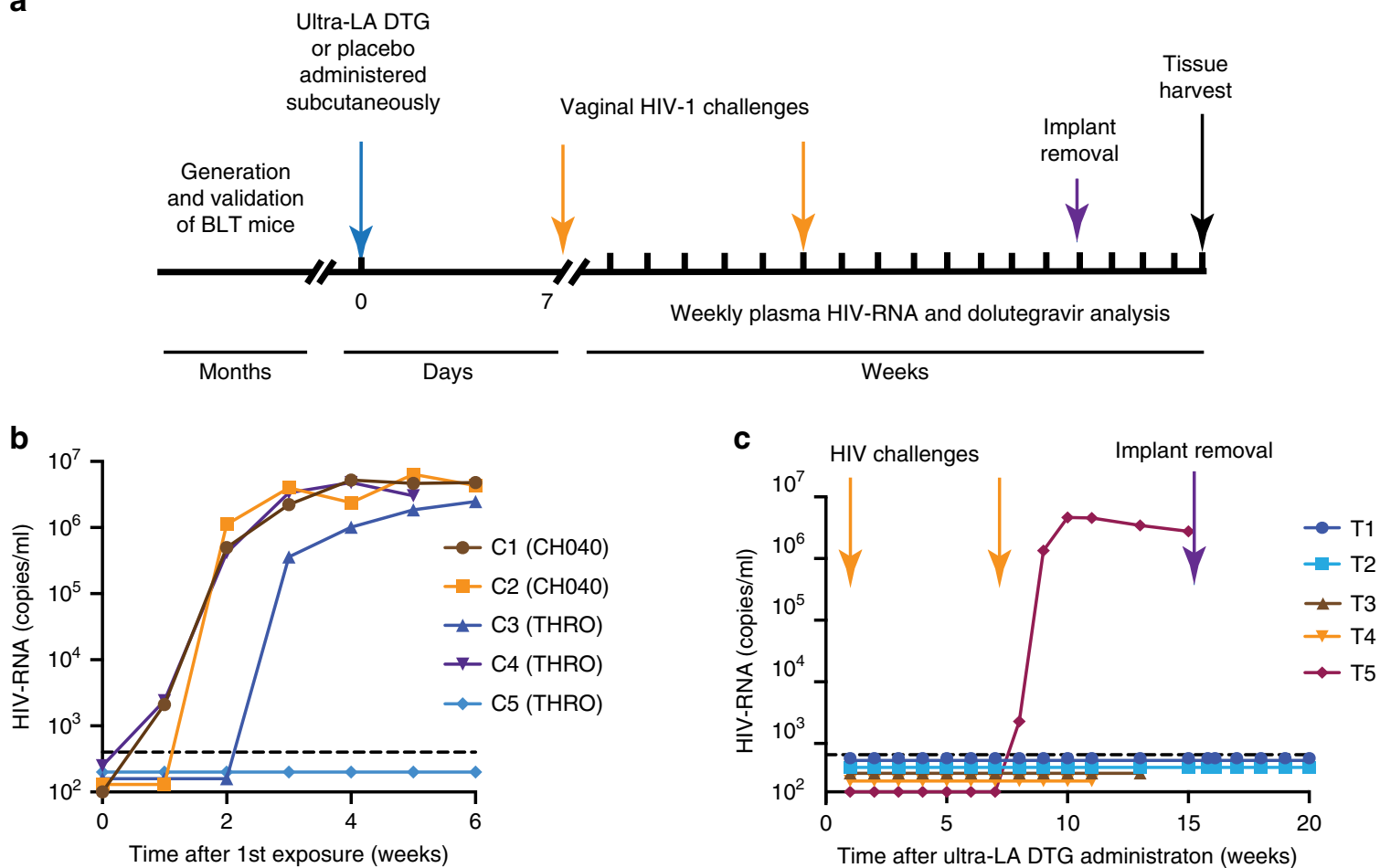

d
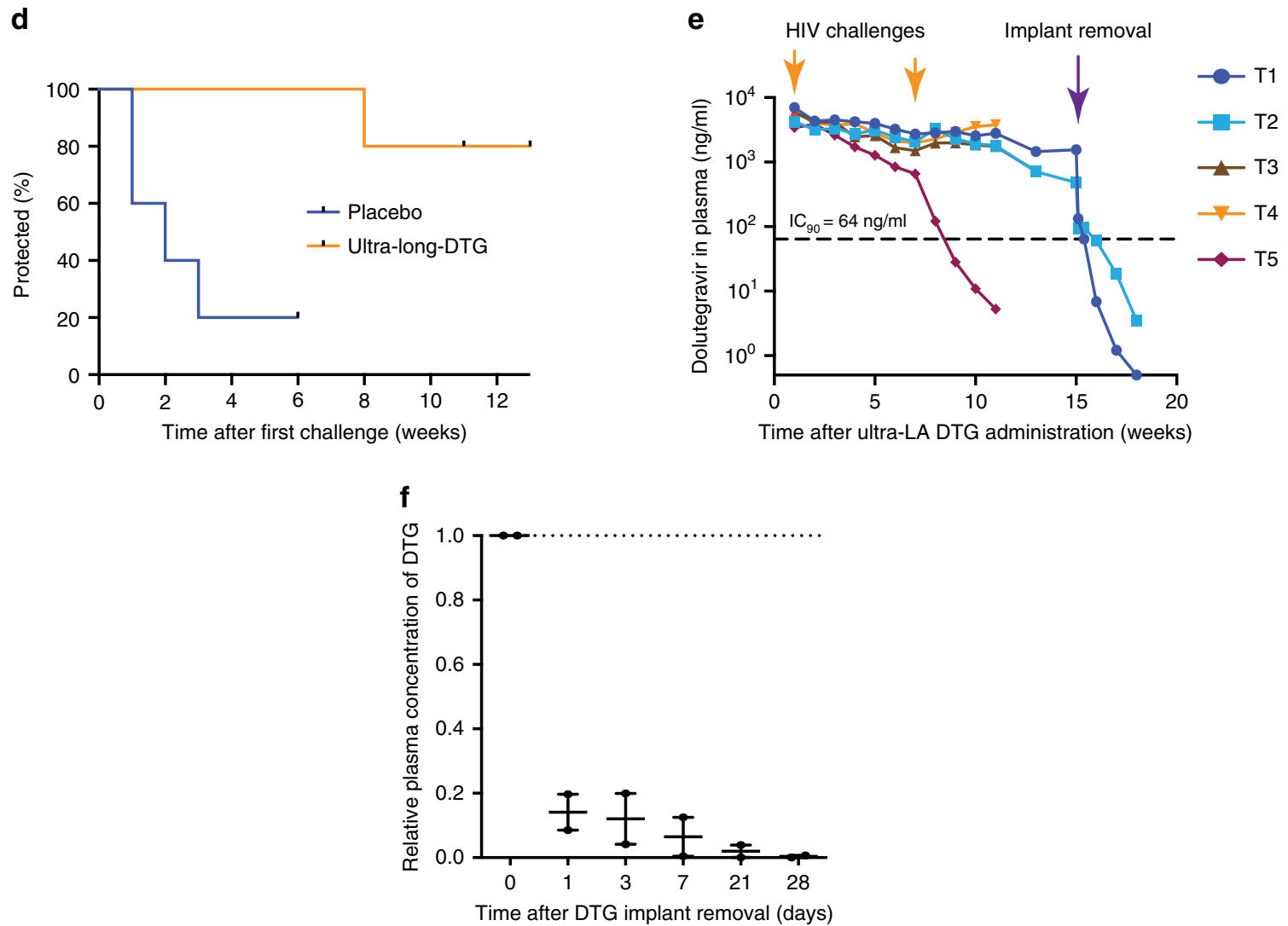

Fig. 4 A single dose of ultra-LA dolutegravir protects against multiple high dose HIV-1 challenges. a Experimental design. BLT mice were treated with ultraLA dolutegravir $(n=5)$ or placebo $(n=5)$ and vaginally exposed to $\mathrm{HIV}_{\mathrm{CHO} 40}$ or $\mathrm{HIV}_{\mathrm{THRO}} 1$ week, and 7 weeks later. The implant was removed from two mice 8 weeks after second HIV challenge. Cell-associated HIV-DNA in multiple tissues was analyzed at the end of the experiment. Plasma HIV-RNA concentration in control $(\mathbf{b})$ and treated mice $(\mathbf{c})$. d Time-to-events plot illustrating the estimated probability of protection $(p=0.02)$. e Plasma concentration of dolutegravir. $\mathbf{f}$ Plasma concentration of dolutegravir $(n=2)$ after the implant removal relative to dolutegravir concentration immediately before the implant removal (dotted line). Individual measurements and median \pm range is shown. Experiment was conducted once 
Table 4 BLT mice protection with ultra-LA-DTG from high dose vaginal HIV-1 challenges

\begin{tabular}{|c|c|c|c|c|c|c|c|c|c|c|c|c|}
\hline Mouse & hCD45 (\%) & hCD4 (\%) & Treatment & $\begin{array}{l}\text { Virus for 1st } \\
\text { challenge }\end{array}$ & $\begin{array}{l}\text { Virus for 2nd } \\
\text { challenge }\end{array}$ & $\begin{array}{l}\text { Infecting } \\
\text { virus }\end{array}$ & \multicolumn{6}{|c|}{ Presence of viral DNA in tissues } \\
\hline C2 & 84.0 & 92.4 & Vehicle & $\mathrm{CHO} 40$ & None & $\mathrm{CHO} 40$ & + & + & + & + & + & + \\
\hline C3 & 74.0 & 86.9 & Vehicle & THRO & None & THRO & + & + & + & + & + & + \\
\hline C4 & 84.3 & 87.2 & Vehicle & THRO & None & THRO & + & + & + & + & + & + \\
\hline $\mathrm{T} 2$ & 84.4 & 88.4 & LA-DTG & $\mathrm{CHO} 40$ & $\mathrm{CHO} 40$ & None & - & - & - & - & - & - \\
\hline T3 & 73.2 & 89.8 & LA-DTG & THRO & $\mathrm{CHO} 40$ & None & - & - & - & - & - & - \\
\hline T4 & 80.2 & 91.9 & LA-DTG & THRO & $\mathrm{CHO} 40$ & None & - & - & - & - & - & - \\
\hline T5 & 67.2 & 93.0 & LA-DTG & $\mathrm{CHO} 40$ & $\mathrm{CHO} 40$ & $\mathrm{CHO} 40$ & + & + & + & + & + & + \\
\hline Mean & 76.6 & 88.5 & & & & & & & & & & \\
\hline SD & 21.0 & 12.2 & & & & & & & & & & \\
\hline
\end{tabular}

suggest utility of humanized mouse models for pre-clinical evaluation of LA formulation of AVR.

Optimally, a LA delivery system for HIV prophylaxis should be effective, safe, easy to apply, and affordable so that it can be used in resource-poor and constrained settings. The data in this paper indicate that ultra-LA dolutegravir can be readily prepared and sterilized by filtration. It can efficiently deliver dolutegravir for up to 9 months in mice and 140 days in NHP (last time point analyzed). A single administration of ultra-LA dolutegravir strongly inhibited acute HIV replication, and effectively protected against repeated high-dose vaginal HIV challenges using highly relevant primary transmitted/founder viruses. An important aspect of the ultra-LA dolutegravir formulation is the fact that it can be easily removed resulting in rapid decrease of drug concentration providing a measure of safety that is not afforded by any of the current LA drug delivery systems in clinical trials for HIV prevention. However, when immediate removal is not necessary, the formulation is biodegradable and does not require surgical removal. In addition, the formulations offer the flexibility to include multiple drugs and the future potential to be reloadable in $\operatorname{situ}^{31}$.

In this stage of formulation development, it is difficult to predict how much ultra-LA dolutegravir will be needed to achieve same efficacy of prevention from HIV transmission as seen in BLT mice. However, we can compare this formulation to existing LA formulations in clinical trials. Cabotegravir nanoformulation consists of two 2-ml injections of product containing $200 \mathrm{mg} / \mathrm{ml}$ drug administered every 2 months. Our goal is to develop a formulation that can accommodate $250 \mathrm{mg} / \mathrm{ml}$ dolutegravir. As the IC90 for dolutegravir $(64 \mathrm{ng} / \mathrm{ml})$ is 2.5 -fold lower that the IC90 for cabotegravir $(166 \mathrm{ng} / \mathrm{ml})$ we consider this to be an appropriate target. PK analysis shown in Fig. 1 also suggests longer sustained release of dolutegravir in vivo compared to the current cabotegravir formulation. Therefore, using the same parameters currently used for cabotegravir, our ultra-LA dolutegravir is likely scalable to humans.

This technology was inspired from the Atrigel product that is commercially available as Eligard (please see citation 8 and 9). This is a palliative treatment for advanced prostate cancer. However, there are several differences between Eligard and our ultra-LA delivery system. (1) Eligard is packaged as a 2-syringe system due to the limited stability of leuprolide acetate in the PLGA/NMP formulation and administered as a dispersion rather than a solution $^{32}$. (2) The ultra-LA dolutegravir formulation presented in this manuscript uses an antiretroviral drug instead of a synthetic hormone, (3) the formulation is prepared as a solution that is stable for more than 6 months at room temperature. Since the Atrigel technology has already been approved by the FDA for treatment of prostate cancer we anticipate that it is also applicable for HIV PrEP.

Several key observations are worth highlighting. Dolutegravir monotherapy resulted in strong and sustained suppression of HIV replication. However, as early as 19 days post therapy initiation, resistance mutations begun to appear in the replicating viruses. By day 50 post therapy initiation, both drug resistance and compensatory mutations were found. Consistent with studies in women ${ }^{18}$, the concentration of dolutegravir in FRT tissues from BLT mice was 3-7 times lower than in plasma. However, even under these conditions significant protection from high dose vaginal infection was noted. The one case of breakthrough infection could be attributed to the lower drug concentration present in this mouse at or near the time of exposure $(659 \mathrm{ng} / \mathrm{ml})$. Of note, the dolutegravir plasma concentrations sustained in the mice protected from high dose HIV infection $(\sim 2800 \mathrm{ng} / \mathrm{ml})$ are directly comparable to those of cabotegravir reported to be protective in a non-human primate model of low dose repeated exposure vaginal SHIV infection ${ }^{33}$. In summary, the results demonstrate the in vivo effectiveness of an ultra-LA formulation of dolutegravir to deliver drug for up to 9 months that results in sustained viral suppression and prolonged protection from high dose HIV vaginal challenges. With its ultra-long duration, low cost of production, ease of administration and the ability to be removed this represents a significant advance in drug delivery for HIV pre-exposure prophylaxis.

\section{Methods}

Chemicals. 50:50 Poly(DL-lactide-co-glycolide) was purchased from LACTEL (Birmingham, AL; Cat. No. B6010-1P, MW $27 \mathrm{kDa}$ ). $N$-methyl-2-pyrrolidone (NMP) was purchased from ASHLAND (Wilmington, DE, Product Code 851263, $100 \%$ NMP). Dolutegravir (DTG) was purchased from Selleckchem (Houston, TX; Cat. No. S2667, 99.8\% DTG).

Preparation of ultra-LA dolutegravir formulations. In a $7 \mathrm{~mL}$ scintillation vial back-filled with argon, 50:50 Poly(DL-lactide-co-glycolide) (PLGA) was mixed with $\mathrm{N}$-methyl-2-pyrrolidone (NMP) at a 1:2 PLGA/NMP weight ratio (w/w) and allowed to dissolve by continuous mixing at room temperature (Placebo). Formulation was sterilized by filtration $(0.2 \mu \mathrm{m}$ filter). Dolutegravir (DTG) was 
subsequently added to the PLGA/NMP solution and stirred at $40^{\circ} \mathrm{C}$ for $2 \mathrm{~h}$ to dissolve DTG and produce an ultra-LA dolutegravir formulation with a final concentration of dolutegravir $93 \mathrm{mg} / \mathrm{mL}$ (ultra-LA dolutegravir; DTG/PLGA/NMP $=0.3: 1: 2 \mathrm{w} / \mathrm{w} / \mathrm{w})$. The viscosity of the ultra-LA dolutegravir $(845 \mathrm{cP})$ was measured using a Brookfield Cone and Plate Digital Rheometer (Model: LVDV-III+CP) and the reading was recorded at $25^{\circ} \mathrm{C}$ and $1 \mathrm{rpm}$. The chemical stability of DTG in the ultra-LA dolutegravir formulation (DTG/PLGA/NMP 0.3:1:2 w/w/w) was measured at $25^{\circ} \mathrm{C}$ over 90 days. The ultra-LA dolutegravir formulation remained as a solution for 90 days as measured by dynamic light scattering (DLS, a Zetasizer Nano ZS Particle Analyzer (Malvern Instruments, Inc.). In addition, DTG concentration at day 90 was $\sim 98 \%$ the original concentration $(91 \pm 0.6 \mathrm{mg} / \mathrm{mL})$ as measured by HPLC analysis using a Finnigan Surveyor HPLC system (Thermo Finnigan, San Jose, CA) with a Photodiode Array (PDA) Plus Detector, autosampler, and LC Pump Plus. The stationary phase utilized for the analysis was a Inertsil ODS-3 column $(5 \mu \mathrm{m}, 4.6 \times 150 \mathrm{~mm}$, [GL Sciences, Torrance, CA] $)$ maintained at $40^{\circ} \mathrm{C}$. Chromatographic separation was achieved by gradient elution using a mobile phase consisting of $0.1 \%$ trifluoroacetic acid in water and acetonitrile $(\mathrm{ACN})\left(\mathrm{H}_{2} \mathrm{O} / \mathrm{ACN} 95: 5 \mathrm{v} / \mathrm{v}\right)$. The flow rate was $1.0 \mathrm{~mL} / \mathrm{min}$ and the total run time was $25 \mathrm{~min}$ for each $25 \mu \mathrm{L}$ injection. Implant formation in vitro was instantaneous upon injection of the formulation in the aqueous release medium (0.01 M PBS, $\mathrm{pH}=7.4,2 \%$ solutol).

BLT humanized mice and non-human primates. BLT humanized mice were prepared by implanting a sandwich of human thymus-liver-thymus tissue under the kidney capsule of irradiated (200 rads) 8-12 weeks old female NOD/SCID $/ \gamma \mathrm{c}^{-1-}$ (NSG) mice (The Jackson Laboratory, Bar Harbor, ME). Following tissue implantation, mice received autologous $\mathrm{CD} 34^{+}$hematopoietic stem cells via tail vein injection. Starting at 8 weeks post transplantation, human immune cell reconstitution was monitored in the peripheral blood of BLT mice by flow cytometry longitudinally. Specifically, concentration of human cells (human CD45+ cells, BD Pharmingen ${ }^{\mathrm{m}}$ APC Mouse Anti-Human CD45, cat. \#555485, 1:100), human T cells (human CD45 +CD3+ cells, BD Pharmingen ${ }^{\text {me }}$ FITC Mouse Anti-Human CD3, cat. \#555339, 1:100) and human CD4 T cells (human CD45+CD3+CD4+ cells, BD Pharmingen ${ }^{\mathrm{nx}}$ PE Mouse Anti-Human CD4, cat. \#555347, 1:100) were determined and mice with $\geq 40 \%$ human $\mathrm{CD}_{4} 5^{+}$cells ( 3 months after humanization) were used for experiments ${ }^{12,34-37}$. Due to the focus on prevention of vaginal HIV transmission, only female mice were used for the experiments. Mice were maintained by the Division of Comparative Medicine at UNC-Chapel Hill according to protocol approved by the Institutional Use and Care Committee under AAALAC guidelines. Two rhesus macaques (Macaca mulatta) were used for the in vivo evaluation of the ultra-LA dolutegravir. Animals were maintained at the CDC Roybal Campus animal facility in Atlanta, Georgia, all procedures were performed by the Comparative Medicine Branch (CMB) with certified attending DVMs and trained staff. All animal protocols have been approved by the onsite IACUC under AAALAC guidelines.

\section{Administration of ultra-LA-DTG and sample collection. Liquid ultra-LA} dolutegravir $(250 \mathrm{mg} / \mathrm{kg}$ in $50-80 \mu \mathrm{l})$ or a similar volume of placebo formulations were administered subcutaneously with a $19 \mathrm{G}$ needle on the shaved back of anesthetized BLT or NSG mice. Peripheral blood was collected from mice into capillary tubes coated with or without EDTA to isolate plasma or serum, respectively. CVS were obtained by lavage with sterile PBS (three washes of $20 \mu \mathrm{l}$ each, $\sim 60 \mu \mathrm{l}$ total volume). All samples were stored at $-80^{\circ} \mathrm{C}$ until analysis. Similarly, ultra-LA dolutegravir formulation was administered to two rhesus macaques via subcutaneous injection. The administration site was clipped of hair and aseptically treated with povidone iodine or chlorhexiderm and isopropanol on the day of implantation. Formulation was administered subcutaneously under anesthesia using a $19 \mathrm{G}$ needle. Injections were done above the thoracic vertebrae $\mathrm{T} 1 / \mathrm{T} 2^{16}$. We used a custom-made primate jacket and a T-shirt under to avoid animal scratching. Animals went through an acclimation period for the jackets prior to the implantation. The jackets are not restrictive and do not interfere with movement or eating. Peripheral blood samples were collected and analyzed for drug concentrations essentially as indicated above.

Implant removal from BLT mice. Mice were anesthetized and their back was shaved to visualize the location of the implant. Implant was removed under sterile conditions via a small cutaneous incision adjacent to the implant and removing the implant using forceps.

\footnotetext{
Analysis of dolutegravir in plasma and tissues. Quantification of DTG plasma concentrations was performed by protein precipitation and LC-MS/MS analysis. Calibration curves were obtained using a $1 /$ concentration $^{2}$ weighted linear regression of analyte:internal standard peak area ratio versus nominal concentration. Compilation of concentration results and descriptive statistical analyses were performed using Sciex Analyst version 1.6.1. Ten microliters of each stored plasma sample was mixed with $30 \mu \mathrm{L}$ of acetonitrile containing the isotopically labeled internal standard, dolutegravir- $\mathrm{d}_{7}{ }^{15} \mathrm{~N}$ (DTG-IS). Following vigorous mixing and centrifugation, a portion of the supernatant was diluted with 50:50 methanol:water prior to LC-MS/MS analysis. DTG was eluted from a Varian (Agilent) Pursuit Diphenyl $(2.1 \times 50 \mathrm{~mm}, 3 \mu \mathrm{m}$ particle size $)$ analytical column. An API- 5000 triple
}

quadrupole mass spectrometer (AB Sciex, Foster City, CA) was used to detect the analyte. For DTG, the precursor ion was $420 \mathrm{~m} / \mathrm{z}$ and the product ion was $277 \mathrm{~m} / \mathrm{z}$ For DTG-IS, the precursor ion was $428 \mathrm{~m} / \mathrm{z}$ and the product ion was $283 \mathrm{~m} / \mathrm{z}$. The data were collected using AB Sciex Analyst Chromatography Software. The dynamic range of the assay was $1-10,000 \mathrm{ng} / \mathrm{mL}$. All calibrators and quality control (QC) samples were within $15 \%$ of the nominal value for both within-day and between-day runs. The high, medium, and low QC values used for plasma were $3.00,300$, and $3000 \mathrm{ng} / \mathrm{mL}$. Within-day and between-day precision calculations were $<15 \%$. The recovery range for DTG in plasma was $98.0-103 \%$, and the recovery of DTG-IS was $104 \%$.

Thirty microliters of each vaginal wash sample was mixed with $270 \mu \mathrm{L}$ of acetonitrile containing DTG-IS. Following vortex and centrifugation, a portion of the supernatant was diluted with 50:50 methanol:water. DTG was detected using identical conditions to those described for plasma. The dynamic range of the assay was $1-1000 \mathrm{ng} / \mathrm{mL}$. The recovery range for DTG in CVF was $99.4-105 \%$, and the recovery of DTG-IS was $101 \%$. All calibrators and quality controls samples were within $15 \%$ of the nominal value. The low, medium, and high QC values used for CVF were 3.00, 30.0, and $800 \mathrm{ng} / \mathrm{mL}$. Within-day and between-day precision was $<15 \%$.

In order to extract DTG from tissue samples, they were initially homogenized in $1 \mathrm{~mL}$ of 80:20 water:acetonitrile. Fifty microliters of the resulting homogenate was extracted by protein precipitation with acetonitrile containing DTG-IS. Following vortex and centrifugation, a portion of the supernatant was diluted with water. DTG was detected on an LC-MS/MS system using identical conditions as described above. During method validation, calibration standards were prepared in mouse tissue homogenate. QC samples were prepared in mouse genital tract tissue homogenates. The dynamic range of the assay was $0.2-200 \mathrm{ng} / \mathrm{mL}$ homogenate. The recovery range of DTG in tissue homogenate was 50.7-63.4\%, and the recovery of DTG-IS was $72.0 \%$. All calibrators and quality controls samples were within $15 \%$ of the nominal value with precision values $<15 \%$. The low, medium, and high QC values used for tissues were $0.600,6.00$, and $160 \mathrm{ng} / \mathrm{mL}$, respectively.

Preparation of HIV-1 stocks for infection. Viral stocks of HIV-1 $1_{\text {JR-CSF }}$ HIV$1_{\mathrm{CH} 040}$, and HIV- $1_{\text {THRO }}$ were generated by transfecting proviral DNA ${ }^{38-42}$ into 293T cells (American Tissue Culture Collection, catalog number CRL-3216, passage $<10)$ using Lipofectamine 2000 (Invitrogen). Viral particles were collected from tissue culture medium, pre-cleared by centrifugation (3000 RPM for $20 \mathrm{~min}$ at $4^{\circ} \mathrm{C}$ ) and concentrated by ultracentrifugation (31,000 RPM for 70 min at $4{ }^{\circ} \mathrm{C}$ ). Tissue culture infectious units (TCID)/ml of HIV was determined by titration on TZM-bl cells (NIH AIDS Research and Reference Reagent Program, catalog number 8129 , passage number 2-6), infected TZM-bl cells were visualized by with staining solution $(4 \mu \mathrm{M}$ potassium ferrocyanide, $4 \mu \mathrm{M}$ potassium ferricyanide, 2 $\mu \mathrm{M}$ magnesium chloride, $0.4 \mathrm{mg} / \mathrm{ml} \mathrm{X-gal})^{12,43}$. TZM-bl and $293 \mathrm{~T}$ cells were cultured at $37^{\circ} \mathrm{C}, 10 \% \mathrm{CO}_{2}$ in Dulbecco's Modified Eagle Medium (Sigma) supplemented with $10 \%$ fetal bovine serum, $25 \mathrm{mM}$ HEPES, 500 units $/ \mathrm{ml}$ penicillin, 50 $\mu \mathrm{g} / \mathrm{ml}$ streptomycin and $2 \mathrm{mM}$ L-glutamine (Cellgro), cells were regularly checked for morphology by microscope.

In vitro HIV-1 inhibition. TZM-bl cells were maintained in TZM-bl medium as described above and cultured at $37^{\circ} \mathrm{C}$ and $5 \% \mathrm{CO}_{2}$. TZM-bl cells were plated in 96 well plates at a density of $1 \times 10^{5}$ cells per well in TZM-bl medium. The next day, the medium was removed and $100 \mu \mathrm{l}$ of diluted serum from dolutegravir-treated or placebo-treated mice collected 7 day, 28 days, or 84 days post administration was added. Serum was diluted 1:20, 1:100, 1:500, 1:2500, 1:12,500, and 1:62,500 and incubated with cells for $30 \mathrm{~min}$. The cells were infected with $100 \mu \mathrm{l}$ of TZM-bl medium containing $40 \mu \mathrm{g} / \mathrm{ml}$ of DEAE-dextran and $3 \times 10^{3} \mathrm{TCIU}$ of HIV- $1_{\text {JR-CSF }}$ per well was added. Approximately $48 \mathrm{~h}$ later, the medium was removed and the luciferase substrate One-Glo reagent (Promega, Madison, WI) supplemented with $0.2 \%$ Triton X-100 was added to allow for the measurement of luciferase activity and to inactivate virus. Luciferase was measured with a SpectraMax M3 Spectrometer (Molecular Devices, Sunnyvale, CA) and the results normalized to the luciferase activity of cells infected with HIV in the absence of serum and expressed as a percentage of decrease in luciferase activity. The TZM-bl cells were obtained through the NIH AIDS Reagent Program (catalog number 8129, passage number $2-6)$, cells were regularly checked for morphology by microscope.

HIV exposure of BLT mice. For the analysis of the effect of dolutegravir monotherapy on HIV replication, BLT mice were exposed intravenously to $3 \times 10^{4} \mathrm{TCIU}$

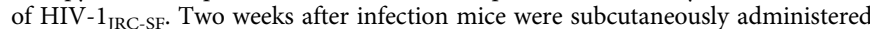
the ultra-LA dolutegravir (or placebo) formulation. To evaluate the ability of the ultra-LA dolutegravir (or placebo) preparation to prevent vaginal HIV transmission following multiple virus challenges, treated BLT mice were exposed vaginally to HIV-1 $1_{\mathrm{CHO} 40}$ or HIV-1 $1_{\text {THRO }} 1$ and 7 weeks after ultra-LA dolutegravir administration. Anesthetized BLT mice were exposed vaginally to $3.0 \times 10^{5}$ TCIU of HIV by pipetting virus $(20 \mu \mathrm{l})$ directly into the vaginal cavity.

Analysis of HIV infection. HIV infection was monitored longitudinally in peripheral blood of BLT mice by determining HIV-RNA concentration in plasma by one-step real-time reverse transcriptase PCR assay, using the following primers: 
CATGTTTTCAGCATTATCAGAAGGA, TGCTTGATGTCCCCCCACT, and the MGB-probe carboxyfluorescein (FAM)-CCACCCCACAAGATTTAAACACCAT GCTAA-Q (non-fluorescent quencher) (Applied Biosystems) (assay sensitivity of 1375 HIV-RNA copies/ml). The presence of HIV-DNA in tissues (spleen, lymph nodes, bone marrow, human thymus, liver, lung, and FRT) collected from BLT mice at necropsy was determined by real-time PCR analysis of DNA extracted from isolated mononuclear cells (assay limit of detection: 28 copies) with same primers and HIV-RNA (Supplementary Table 1). As a control for the presence of DNA extracted from human cells, all samples were tested for the presence of human gamma globin DNA by real-time PCR using primers: CGCTTCTGGAACGTCTGAGATT (forward), CCTTGTCCTCCTCCTCTGTGAAATGA (reverse) (Supplementary table 1). Concentration of human cells (human CD45+ cells, BD Pharmingen ${ }^{\text {mt }}$ APC Mouse Anti-Human CD45, cat. \#555485, 1:100), human T cells (human CD45+CD3 + cells, BD Pharmingen ${ }^{\mathrm{m}}$ FITC Mouse Anti-Human CD3, cat. \#555339, 1:100) and human CD4 T cells (human CD45+CD3+CD4+ cells, BD Pharmingen" PE Mouse Anti-Human CD4, cat. \#555347, 1:100) were determined using a BD FACSCanto ${ }^{\mathrm{TM}}$ flow cytometer and analyzed using FlowJo software (FLOWJO, LLC, version 10.0.8).

Sequence analysis of infecting viruses. The identity of the infecting viruses was determined by sequence analysis. Viral RNA was isolated from plasma using QIAamp viral RNA columns (Qiagen, Hilden, Germany) according to the manufacturer's protocol, and cDNA was generated using Superscript III Reverse Transcriptase (Invitrogen, Carlsbad, CA) with the primer 5'-CTTCCAATTATGT TGACAGGTGTAGG-3'. cDNA was amplified by nested PCR using the Expand High Fidelity PCR System (Roche, Mannheim, Germany). PCR primers were designed to anneal in regions with the fewest possible primer mismatches to HIV$1_{\mathrm{CHO} 40}, \mathrm{HIV}-1_{\mathrm{IR}-\mathrm{CSF}}$, and HIV- $1_{\mathrm{THRO}}$ sequences. Primer sequences were as follows: outer forward primer, 5'-CTCAATAAAGCTTGCCTTGAGTGC-3'; outer reverse prime 5'-CTTCCAATTATGTTGACAGGTGTAGG-3'; inner forward primer, 5'GTGTGGAAAATCTCTAGCAGTGGC-3'; inner reverse primer 5'-CTGTATCAT CTGCTCCTGTATCTAATAGAGC-3' (Supplementary Table 1). Amplified viral DNA of gag was sequenced and compared to the sequences of challenge viruses.

To identify the emergence of drug-resistant mutations in the breakthrough viruses from BLT mice receiving ultra-LA dolutegravir PrEP or BLT mice suppressed with ultra-LA dolutegravir monotherapy, viral RNA was extracted from plasma using QIAamp viral RNA kit (Qiagen, Hilden, Germany). cDNA was generated from RNA with Superscript III RT (Invitrogen, Carlsbad, CA) with primer 5'-GGTCAGGGTCTACTTGTGTGC-3' followed by nested PCR with Expand High Fidelity Kit (Roche, Mannheim, Germany) to amplify $1.5 \mathrm{~kb}$ region of reverse transcriptase. The following primers were used: forward outer primer $5^{\prime}-\mathrm{C}$ CTGAGTGGGAGTTTGTCAATAC-3', reverse outer primer 5'-GGTCAGGGT CTACTTGTGTGC-3', forward inner primer 5'-AGCACACAAAGGAATTGGA G-3' reverse inner primer $5^{\prime}$-GTGGGATTTGTACTTCTGAAC-3' (Supplementary Table 1). Amplified viral DNA of integrase was sequenced and compared to the sequence of the original HIV-1 used for infection. To further characterize the mutations found, cDNA were cloned (6-10 clones), sequenced and analyzed. FinchTV software (Geospiza, Seattle, WA) was used to analyze sequence chromatograms, NCBI BLAST to identify sequence, and ClustalW to align sequences.

Statistical analysis. All data were graphed using GraphPad Prism (version 6.0) The statistical tests used are indicated in the figure legends and/or text.

For PK analysis in plasma and tissues, dolutegravir concentrations $(\mathrm{ng} / \mathrm{ml}$ or $\mathrm{ng} / \mathrm{g}$ ) in plasma, and tissue from the cervix, uterus, and vagina, (Fig. 1c) were measured in 18 mice with six mice observed at each time point (days 7, 28, and 84). Different mice contributed to each time point because the animals were collected to measure tissue concentrations; the same design was used for plasma analysis. Dolutegravir levels were compared between the three time points using an exact Kruskal-Wallis test to test for any statistically significant difference, with each sample type (plasma, cervix, uterus, vagina) analyzed separately. Ratios of plasma: tissue concentration within mouse were evaluated using an exact Wilcoxon signedrank test [Ho: plasma: tissue ratio $=1$, i.e., $\log ($ plasma DTG $)-\log ($ tissue $\mathrm{DTG})=0$ ]; observations were combined over the three time points and each tissue type was analyzed separately. A 0.05 statistical significance level was used with no adjustment for multiple testing; two-sided tests were used throughout. Seven (7) null hypothesis significance tests were conducted in this report.

A non-parametric rank-based correlation analysis accounting for clustered observations (Kendall's tau) was used to compare in vitro inhibitory activity (\%) of serum from ultra-LA dolutegravir-treated mice and $\log _{10}$ concentration of dolutegravir (Fig. 2c) ${ }^{44}$

For the suppression experiment (Fig. 3) the outcomes of plasma viral load, (CVS) cervical vaginal secretion viral load, and $\mathrm{hCD} 4^{+} \mathrm{T}$-cell concentration, area under the curve (AUC) was calculated using the trapezoid method over 11 longitudinal measurements (taken between days 1 and 42) and compared between the control and dolutegravir-treated groups. A generalization of the exact Wilcoxon-Mann-Whitney test was used to account for interval-censored observations arising from HIV RNA results below the limit of detection (LOQ $)^{45}$ Lower and upper bounds for the AUC were computed using zero and the LOQ, respectively, for results below the limit. In the absence of censoring (e.g., hCD4\%) this test reduces to the exact Wilcoxon rank-sum test. Notably, one mouse in the control group died after six longitudinal measurements and was assigned the worst ranked AUC for analysis (i.e., the largest viral load AUCs and lowest hCD4 \% AUC). Analyses were conducted in SAS version 9.4 (Cary, NC) and R-project version 3.4.0.

An exact log rank test was used to compare protection between placebo and ultra-LA dolutegravir-treated BLT mice (Fig. 4d). If not otherwise specified, standard error of the mean was used to estimate variation within each group. Variance is similar between the groups that are being statistically compared. No statistical methods were used to pre-determine the sample size. No randomization was used to determine how samples/animals were allocated to experimental groups. Mice representing the same human donor were allocated to each experimental group. Each experimental group had animals with similar levels of humanization. Blinding was used to analyze plasma concentration of HIV-RNA and concentration of cell-associated HIV-RNA and HIV-DNA. Investigators were given numbered samples, but not the allocation of the samples to groups (treated, controls). No other blinding was used.

Code availability. Following commercially available software were used for data collection and analysis. For data collection (FACS), BD FACSDiva software (version 6.1.3) was used. The data were analyzed using FlowJo software (version 10), Microsoft Excel (2016), GraphPad Prism (versions 6), SAS version 9.4 and Rproject version 3.4.0.

\section{Data availability}

Sequence data that support the findings in Table 3 of this study have been deposited in GenBank with the accession codes: MH425196-MH425242. The authors declare that all other data supporting the findings of this study are available within the article and its Supplementary Information files, or are available from the authors upon request.

Received: 19 April 2018 Accepted: 29 August 2018

Published online: 08 October 2018

\section{References}

1. Osterberg, L. \& Blaschke, T. Adherence to medication. N. Engl. J. Med. $\mathbf{3 5 3}$, 487-497 (2005)

2. McEvoy, J. P. Risks versus benefits of different types of long-acting injectable antipsychotics. J. Clin. Psychiatry 67, 15-18 (2006).

3. Winner, B. et al. Effectiveness of long-acting reversible contraception. N. Engl. J. Med. 366, 1998-2007 (2012).

4. Meyers, K. et al. High interest in a long-acting injectable formulation of preexposure prophylaxis for HIV in young men who have sex with men in NYC a P18 cohort substudy. PLoS ONE 9, https://doi.org/10.1371/journal. pone.0114700 (2014).

5. PATH. HPTN 076 - Phase II safety and acceptability of an investigational injectable product, TMC278 LA, for pre-exposure prophylaxis (PrEP). ClinicalTrials.gov, clinicaltrials.gov/ct2/show/NCT02165202?term $=$ HPTN +076 \&rank $=1$ (2014)

6. National Institute of Allergy and Infectious Diseases. A phase IIa study to evaluate the safety, tolerability and pharmacokinetics of the investigational injectable HIV integrase inhibitor, GSK1265744, in HIV-uninfected men and women. ClinicalTrials.gov, https://www.clinicaltrials.gov/ct2/show/ NCT02178800?term $=$ HPTN077\&rank=1 (2014).

7. National Institute of Allergy and Infectious Diseases. A phase $2 b / 3$ double blind safety and efficacy study of injectable cabotegravir compared to daily oral tenofovir disoproxil fumarate/emtricitabine (TDF/FTC), for pre-exposure prophylaxis in HIV-uninfected cisgender men and transgender women who have sex with men. ClinicalTrials.gov, https://www.clinicaltrials.gov/ct2/show/ NCT02720094?term $=$ NCT02720094\&rank $=1$ (2016).

8. Dunn, R. L., English, J. P., Cowsar, D. R. \& Vanderbult, D. P. Biodegradable in-situ forming implants and methods of producing the same. USA Pat. 5, 194 (1999).

9. Dunn, R. L. \& Tipton, A. J. Polymeric compositions useful as controlled release implants. USA Pat. 5, 716 (1997).

10. Melkus, M. W. et al. Humanized mice mount specific adaptive and innate immune responses to EBV and TSST-1. Nat. Med. 12, 1316-1322 (2006).

11. Olesen, R. et al. ART influences HIV persistence in the female reproductive tract and cervicovaginal secretions. J. Clin. Invest. 126, 892-904 (2016).

12. Kovarova, M. et al. Nanoformulations of rilpivirine for topical pericoital and systemic coitus-independent administration efficiently prevent HIV transmission. PLoS Pathog. 11, https://doi.org/10.1371/journal.ppat.1005075 (2015).

13. Kovarova, M. et al. A long-acting formulation of the integrase inhibitor raltegravir protects humanized BLT mice from repeated high-dose vaginal HIV challenges. J. Antimicrob. Chemother. 71, 1586-1596 (2016). 
14. Denton, P. W. et al. Generation of HIV latency in BLT humanized mice. J. Virol. 86, 630-634 (2012).

15. Cottrell, M. L., Hadzic, T. \& Kashuba, A. D. Clinical pharmacokinetic, pharmacodynamic and drug-interaction profile of the integrase inhibitor dolutegravir. Clin. Pharmacokinet. 52, 981-994 (2013).

16. Royals, M. A. et al. Biocompatibility of a biodegradable in situ forming implant system in rhesus monkeys. J. Biomed. Mater. Res. 45, 231-239 (1999).

17. Jouyban, A., Fakhree, M. A. \& Shayanfar, A. Review of pharmaceutical applications of N-methyl-2-pyrrolidone. J. Pharm. Pharm. Sci. 13, 524-535 (2010).

18. Adams, J. L. et al. Single and multiple dose pharmacokinetics of dolutegravir in the genital tract of HIV-negative women. Antivir. Ther. 18, 1005-1013 (2013).

19. Anstett, K., Cutillas, V., Fusco, R., Mesplede, T. \& Wainberg, M. A. Polymorphic substitution E157Q in HIV-1 integrase increases R263Kmediated dolutegravir resistance and decreases DNA binding activity. $J$. Antimicrob. Chemother. 71, 2083-2088 (2016).

20. UNAIDS. UNAIDS Fact Sheet 2018 (UN, 2018).

21. Food and Drug Administration. FDA approves first drug for reducing the risk of sexually acquired HIV infection. AIDS info, https://aidsinfo.nih.gov/news/ 1254/fda-approves-first-drug-for-reducing-the-risk-of-sexually-acquired-hivinfection (2012).

22. Grant, R. M. et al. Preexposure chemoprophylaxis for HIV prevention in men who have sex with men. N. Engl. J. Med. 363, 2587-2599 (2010).

23. Baeten, J. M. et al. Antiretroviral prophylaxis for HIV prevention in heterosexual men and women. N. Engl. J. Med. 367, 399-410 (2012).

24. Thigpen, M. C. et al. Antiretroviral preexposure prophylaxis for heterosexual HIV transmission in Botswana. N. Engl. J. Med. 367, 423-434 (2012).

25. Choopanya, K. et al. Antiretroviral prophylaxis for HIV infection in injecting drug users in Bangkok, Thailand (the Bangkok Tenofovir Study): a randomised, double-blind, placebo-controlled phase 3 trial. Lancet $\mathbf{3 8 1}$ 2083-2090 (2013).

26. Van Damme, L. et al. Preexposure prophylaxis for HIV infection among African women. N. Engl. J. Med. 367, 411-422 (2012).

27. Marrazzo, J. M. et al. Tenofovir-based preexposure prophylaxis for HIV infection among African women. N. Engl. J. Med. 372, 509-518 (2015).

28. Trezza, C., Ford, S. L., Spreen, W., Pan, R. \& Piscitelli, S. Formulation and pharmacology of long-acting cabotegravir. Curr. Opin. HIV AIDS 10, 239-245 (2015).

29. Jackson, A. \& McGowan, I. Long-acting rilpivirine for HIV prevention. Curr. Opin. HIV AIDS 10, 253-257 (2015).

30. Sillman, B. et al. Creation of a long-acting nanoformulated dolutegravir. Nat. Commun. 9, 443 (2018).

31. Brudno, Y. et al. Refilling drug delivery depots through the blood. Proc. Natl Acad. Sci. USA 111, 12722-12727 (2014)

32. Ravivarapu, H. B., Moyer, K. L. \& Dunn, R. L. Parameters affecting the efficacy of a sustained release polymeric implant of leuprolide. Int. J. Pharm. 194, 181-191 (2000).

33. Radzio, J. et al. The long-acting integrase inhibitor GSK744 protects macaques from repeated intravaginal SHIV challenge. Sci. Transl. Med. 7, 270ra275 (2015).

34. Denton, P. W. et al. Antiretroviral pre-exposure prophylaxis prevents vaginal transmission of HIV-1 in humanized BLT mice. PLoS Med. 5, https://doi.org/ 10.1371/journal.pmed.0050016 (2008).

35. Denton, P. W. et al. One percent tenofovir applied topically to humanized BLT mice and used according to the CAPRISA 004 experimental design demonstrates partial protection from vaginal HIV infection, validating the BLT model for evaluation of new microbicide candidates. J. Virol. 85, 7582-7593 (2011).

36. Olesen, R., Wahl, A., Denton, P. W. \& Garcia, J. V. Immune reconstitution of the female reproductive tract of humanized BLT mice and their susceptibility to human immunodeficiency virus infection. J. Reprod. Immunol. 88, 195-203 (2011).

37. Council, O. D., Swanson, M. D., Spagnuolo, R. A., Wahl, A. \& Garcia, J. V. Role of semen on vaginal HIV-1 transmission and maraviroc protection. Antimicrob. Agents Chemother. 59, 7847-7851 (2015).

38. Permar, S. R. et al. Clonal amplification and maternal-infant transmission of nevirapine-resistant HIV-1 variants in breast milk following single-dose nevirapine prophylaxis. Retrovirology 10, https://doi.org/10.1186/1742-4690$10-88(2013)$
39. Keele, B. F. et al. Identification and characterization of transmitted and early founder virus envelopes in primary HIV-1 infection. Proc. Natl Acad. Sci. USA 105, 7552-7557 (2008).

40. Ochsenbauer, C. et al. Generation of transmitted/founder HIV-1 infectious molecular clones and characterization of their replication capacity in CD4 T lymphocytes and monocyte-derived macrophages. J. Virol. 86, 2715-2728 (2012).

41. Salazar-Gonzalez, J. F. et al. Genetic identity, biological phenotype, and evolutionary pathways of transmitted/founder viruses in acute and early HIV1 infection. J. Exp. Med. 206, 1273-1289 (2009).

42. Koyanagi, Y. et al. Dual infection of the central nervous system by AIDS viruses with distinct cellular tropisms. Science 236, 819-822 (1987).

43. Wahl, A. et al. Human breast milk and antiretrovirals dramatically reduce oral HIV-1 transmission in BLT humanized mice. PLoS Pathog. 8, https://doi.org/ 10.1371/journal.ppat.1002732 (2012).

44. Lorenz, D. J., Datta, S. \& Harkema, S. J. Marginal association measures for clustered data. Stat. Med. 30, 3181-3191 (2011).

45. Fay, M. P. \& Shaw, P. A. Exact and asymptotic weighted logrank tests for interval censored data: the interval R package. J. Stat. Softw. 36, i02 (2010).

\section{Acknowledgements}

We thank Dr. John Kappes for HIV-1 CHO40 and THRO which were obtained via the AIDS Research and Reagent Repository Program and current lab members and veterinary technicians at UNC Division of Comparative Medicine for their assistance with various technical aspects of this work. This work was supported by the National Institute of Allergy and Infectious Diseases (grant numbers R01AI131430 to M.K. and S.R.B., KL2TR001109-04 to S.R.B., R01AI073146, R01AI096138, R01AI111899 to J.V.G., and grant number P30AI50410 to UNC Center for AIDS Research). The findings and conclusions in this report are those of the authors and do not necessarily represent the views of the Centers for Disease Control and Prevention (CDC).

\section{Author contributions}

Conceived and designed the experiments: J.V.G., R.J.M., J.G.G.-L., M.K., and S.R.B. Performed the experiments: M.K., S.R.B., I.M., R.A.S., B.S., C.E.B., and C.S. Analyzed the data: M.K., S.R.B., I.M., R.A.S., C.E.B., C.S., K.R.M., and A.D.M.K. Contributed reagents/ materials/analysis tools: S.R.B., C.S., K.R.M., and A.D.M.K. Wrote the paper: M.K., S.R.B., J.V.G., R.J.M., and J.G.G.-L.

\section{Additional information}

Supplementary Information accompanies this paper at https://doi.org/10.1038/s41467018-06490-w.

Competing interests: J.G.G.-L. is named in a US Government patent on "Inhibition of HIV Infection through Chemoprophylaxis". The remaining authors declare no competing interests.

Reprints and permission information is available online at http://npg.nature.com/ reprintsandpermissions/

Publisher's note: Springer Nature remains neutral with regard to jurisdictional claims in published maps and institutional affiliations.

\footnotetext{
(c) (i) Open Access This article is licensed under a Creative Commons Attribution 4.0 International License, which permits use, sharing, adaptation, distribution and reproduction in any medium or format, as long as you give appropriate credit to the original author(s) and the source, provide a link to the Creative Commons license, and indicate if changes were made. The images or other third party material in this article are included in the article's Creative Commons license, unless indicated otherwise in a credit line to the material. If material is not included in the article's Creative Commons license and your intended use is not permitted by statutory regulation or exceeds the permitted use, you will need to obtain permission directly from the copyright holder. To view a copy of this license, visit http://creativecommons.org/ licenses/by/4.0/.
}

(C) The Author(s) 2018 